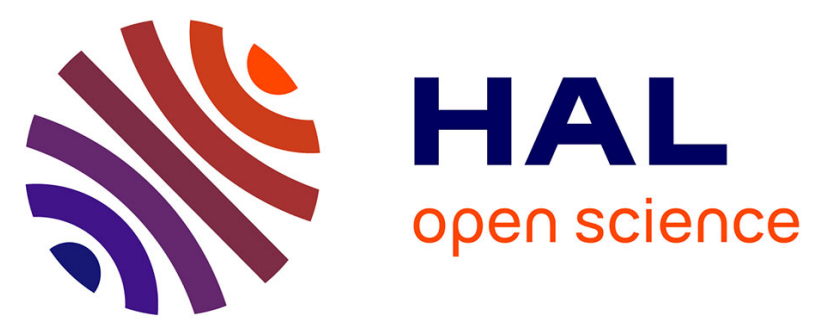

\title{
trans -Resveratrol and trans - $\epsilon$-Viniferin in Grape Canes and Stocks Originating from Savoie Mont Blanc Vineyard Region: Pre-extraction Parameters for Improved Recovery
}

Marion Zwingelstein, Micheline Draye, Jean-Luc Besombes, Christine Piot, Gregory Chatel

\section{To cite this version:}

Marion Zwingelstein, Micheline Draye, Jean-Luc Besombes, Christine Piot, Gregory Chatel. trans -Resveratrol and trans - $\epsilon$-Viniferin in Grape Canes and Stocks Originating from Savoie Mont Blanc Vineyard Region: Pre-extraction Parameters for Improved Recovery. ACS Sustainable Chemistry \& Engineering, 2019, 7 (9), pp.8310-8316. 10.1021/acssuschemeng.8b06723 . hal-02133831

\section{HAL Id: hal-02133831 \\ https://hal.univ-smb.fr/hal-02133831}

Submitted on 9 Mar 2021

HAL is a multi-disciplinary open access archive for the deposit and dissemination of scientific research documents, whether they are published or not. The documents may come from teaching and research institutions in France or abroad, or from public or private research centers.
L'archive ouverte pluridisciplinaire HAL, est destinée au dépôt et à la diffusion de documents scientifiques de niveau recherche, publiés ou non, émanant des établissements d'enseignement et de recherche français ou étrangers, des laboratoires publics ou privés. 


\section{$1 \quad$ Trans-resveratrol and trans-e-viniferin in grape}

2 canes and stocks originating from Savoie Mont

3 Blanc vineyard region: pre-extraction parameters for

4 improved recovery

5 Marion Zwingelstein, ${ }^{\dagger,+}$ Micheline Draye, ${ }^{\dagger}$ Jean-Luc Besombes, ${ }^{\dagger}$ Christine Piot ${ }^{\dagger}$ and Gregory

Chatel $^{\dagger * *}$

$7 \dagger$ Univ. Savoie Mont Blanc, LCME, F-73000 Chambéry, France.

$8 \quad$ † Agence de l'Environnement et de Maîtrise de l'Energie (ADEME), F-49004, Angers, France.

10 KEYWORDS. Stilbenes, viticultural by-products, particles size, vineyard age, storage duration.

12 ABSTRACT. Viticultural by-products are known to contain high-value compounds such as

13 stilbenes. Wine sector in Savoie Mont Blanc region (France) generates high amount of waste

14 including grape canes and grapevine stocks that remain unvalued. Herein, the potential of the most

15 wide-spread grapevine varieties in Savoie Mont Blanc territory, Jacquère and Mondeuse, as

16 sources of two stilbenes, trans-resveratrol (Rsv) and trans-e-viniferin (Vf) was investigated for the

17 first time. Using the reported extraction technique, the present work focused on several pre-

18 extraction parameters influencing the extraction efficiency, including grapevine variety, age of 
19 vines, time of material storage and particles size of the woody material. This work revealed

20 important Rsv and Vf contents in Jacquère residues of 1681-6124 mg. $\mathrm{kg}^{-1} \mathrm{dw}$ and 1620-6667 mg.kg-

$211_{\mathrm{dw}}$ respectively, whereas for Mondeuse variety, the target molecules yields were 1724-4636

$22 \mathrm{mg} \cdot \mathrm{kg}^{-1} \mathrm{dw}$ and $1713-5322 \mathrm{mg} \cdot \mathrm{kg}^{-1} \mathrm{dw}$ respectively. These results are promising when compared with

23 high well-known stilbenes levels in Pinot Noir and Gewurztraminer varieties but also highlight a

24 considerable variability depending on the applied pre-extraction parameters.

\section{INTRODUCTION}

27 A growing demand for natural products in the consumer society emerged in the last decade. ${ }^{1}$ In

28 the same vein, agricultural biomass is of great interest because of its richness in high-value

29 compounds and its abundance. ${ }^{2}$ For example, France was the first exporter and the second largest

30 producer of wine worldwide with a production of 36.7 million hectoliters and a vineyard surface

31 of 787,000 hectares in $2017 .{ }^{3}$ During the winter period, these surfaces produce high amounts of

32 wood-type waste, most of it resulting from the vineyards pruning and consisting in grape canes

33 and grapevine stocks. Theses residues remain unvalued, traditionally burned in vineyards or let on

34 the field, especially on Savoie Mont Blanc territory (France) where the fear of the spread of

35 diseases and the hilly vineyards encourage these practices. However, grapevine by-products are

36 known to contain high-value molecules. ${ }^{4,5}$ Among them, stilbenes are phenolic compounds having

37 considerable importance for the grapevine since they defend the plant against aggressions from

38 pathogenic microorganisms by acting as phytoalexins. ${ }^{6}$ They are derived from the shikimic-

39 polymalonic acid pathway and are biosynthesized by the combination of three malonyl CoA and

40 one $p$-coumaroyl-CoA by stilbene synthase (StSy) to form trans-resveratrol, the first brick of

41 stilbenoid compounds biosynthesis. ${ }^{7,8}$ Trans-resveratrol (5-[(1E)-2-(4-Hydroxyphenyl)ethenyl]- 
42 1,3-benzenediol, CAS: 501-36-0) and its dimer trans-e-viniferin ((3R)-6-hydroxy-2-(4-

43 hydroxyphenyl)-4-[(E)-2-(4-hydroxyphenyl)ethenyl]-2,3-dihydro-1-benzofuran-3-yl]benzene-

44 1,3-diol, CAS: 62218-08-0) are the most studied stilbenes due to their diverse benefits especially

45 in human health and showing anticarcinogenic, cardioprotective and antioxidant properties when

46 used or alone in cocktails of stilbenes. $^{9-11}$

47 Despite their occurrence in plant kingdom, trans-resveratrol (Rsv) and trans- $\varepsilon$-viniferin (Vf) are

48 mainly obtained by chemical synthesis. ${ }^{12,13}$ To a lesser extent, Rsv can be extracted from Japanese

49 knotweed (Fallopia japonica) roots and both compounds can be obtained from skin of grapes and

50 berries but with low purity or also by using biotechnologies (cells culture or enzymatic

51 fermentation). ${ }^{14-17}$ Pinot Noir and Gewurztraminer grape canes, widely studied in the literature,

52 are known to be rich in Rsv and Vf. ${ }^{18-20}$ Extraction techniques used to extract the stilbenes from

53 grape canes are extensive: classical solid-liquid extraction, ultrasound-assisted extraction,

54 microwave-assisted extraction and pressurized solvent extraction for the most recurrent. ${ }^{20-23}$

55 However, data found in literature (Table S1, Supporting information) demonstrate that Rsv and Vf

56 extraction yields differ drastically for the same variety depending on other parameters than the

57 extraction technique.

58 Working from vegetal sources is often problematic because of consequent variations implied by

59 biological diversity. On the other hand, it enables adjustments of all the factors affecting the

60 targeted compounds accumulation in plant. Herein, we propose to investigate several pre-

61 extraction parameters impacting the extraction yields of Rsv and Vf from grape canes of the two

62 most widespread grapevine varieties on Savoie Mont Blanc territory. To the best of our knowledge

63 these typical Savoie Mont Blanc varieties have not been studied yet and could potentially contain

64 high amounts of stilbenes. The investigated parameters included grapevine variety (Jacquère or 
65 Mondeuse), age of vines (5 and 20 years old), particles size of the woody material extracted $(<0.2$

$66 \mathrm{~mm},<0.5 \mathrm{~mm},<1 \mathrm{~mm}$ and $<4 \mathrm{~mm}$ ) and time material storage duration (from 2 to 9 months). A

67 complementary study is provided on the Rsv and Vf contents in Jacquère and Mondeuse stocks

68 and the variability of both compounds contents induced by the vineyard of origin.

\section{EXPERIMENTAL SECTION}

71 Chemicals. Ethanol (96\%) was purchased from VWR, methanol ( $\geq 99 \%)$ from Honeywell, glacial

72 acetic acid $(\geq 99 \%)$ from Fisher Chemical, trans-resveratrol ( $>98 \%)$ from Evolva, trans- $\varepsilon-$

73 viniferin ( $\geq 95 \%$ ) from Extrasynthese and 2-hydroxybenzothiazole (98\%) from Alfa Aesar. All

74 chemicals were used as received, without further purification.

75 Plant material. Jacquère, a white grapevine variety representing $50 \%$ of the viticultural surface 76 on Savoie Mont Blanc territory and Mondeuse a red grapevine variety representing $12 \%$, were 77 selected according to their prevalence in Savoie (Alps, France). The first one was grafted on SO4 78 rootstock (Vitis riparia $x$ Vitis berlandieri) and the second one on 3309 rootstock (Vitis riparia $x$

79 Vitis rupestris). Grape canes and stocks (composed of the upper trunk, the grafting zone and the

80 lower trunk of grapevine plant) of both varieties were collected during February 2018 in a vineyard 81 in agri-environmental and climatic measures at Cruet (entitled "Vineyard 1").

82 Evaluation of variety and age impacts. Jacquère and Mondeuse grape canes were harvested from

83 vines of two types, one of 5 years old and one of 20 years old and were stored during 6 months at

84 room temperature (without access to direct sunlight). For each variety, stocks were also harvested 85 and consisted in a pool of 5 years old and 20 years old vines. They were stored during 9 months at 
86 room temperature (without access to direct sunlight). After storage duration, all samples were dried

87 overnight at $50^{\circ} \mathrm{C}$ and crushed (Pulverisette 19, Fritsch, $<0.5 \mathrm{~mm}$ ).

88 Evaluation of particles size impact. 20 years old Jacquère and Mondeuse grape canes kept at room

89 temperature during (without access to direct sunlight) 6 and 9 months respectively were dried

90 overnight at $50{ }^{\circ} \mathrm{C}$ and then crushed at different particles sizes: $<0.2 \mathrm{~mm},<0.5 \mathrm{~mm},<1 \mathrm{~mm}$ or $<$

$914 \mathrm{~mm}$ (Pulverisette 19, Fritsch). A complementary assay consisted in grinding the rest of the $<4$

$92 \mathrm{~mm}$ particles size batch at a size $<0.2 \mathrm{~mm}$ was also conducted. The impact of particles size was

93 also tested on stocks described above and those of "Vineyard 2" (described in "Evaluation of

94 vineyard origin" section).

95 Evaluation of storage duration. 20 years old Jacquère and Mondeuse grape canes were kept at 96 room temperature (without access to direct sunlight) during 9 months (from February 2018 and 97 November 2018) and batch of canes were collected at 2 months (in April 2018), 6 months (in 98 August 2018) and 9 months (in November 2018) before to be dried overnight at $50{ }^{\circ} \mathrm{C}$ and then 99 crushed (Pulverisette 19, Fritsch, $<0.2 \mathrm{~mm}$ ).

100 Evaluation of vineyard origin. In the same time, 5 years old and 20 years old Jacquère grape canes 101 and Jacquère and Mondeuse stocks were harvested from another vineyard in biological measures 102 at Chignin (entitled "Vineyard 2"). The samples were treated as corresponding samples of 103 Vineyard 1 described in the section "Evaluation of variety and age impacts".

104 Extraction process. All samples were extracted according modified conditions of Pineiro et al.. ${ }^{21}$ $1051 \mathrm{~g}$ of powder was extracted with $30 \mathrm{~mL}$ of ethanol/water $80: 20(\mathrm{v} / \mathrm{v})$ during $1 \mathrm{~h}$ at $60{ }^{\circ} \mathrm{C}$ under 
106

gentle stirring. Extractions from a same batch were performed in 5 replicates. Crude extracts were then filtered $(0.22 \mu \mathrm{m}$, PTFE) without any concentration step prior to HPLC-UV analysis.

High performance liquid chromatographic analysis. Stilbenes characterization and quantification in crude extracts were carried out on a HPLC system with UV detection (Perkin Elmer, Series 200). Separation was performed at $40{ }^{\circ} \mathrm{C}$ on a column packed with $5 \mu \mathrm{m}$ particles (250 x 4.0 mm, Nucleosil 100-5 C18 PAH, Macherey Nagel). Stilbenes were analyzed using a mobile phase gradient consisting of $0.1 \% \mathrm{v} / \mathrm{v}$ of acetic acid in water (solvent $\mathrm{A}$ ) and $0.1 \% \mathrm{v} / \mathrm{v}$ acetic acid in methanol (solvent B) pumped at $1 \mathrm{~mL} \cdot \mathrm{min}^{-1}$ into HPLC system with $5 \mu \mathrm{L}$ as injection volume. The gradient program was as follows: $25-45 \%$ B (from 0 to $5 \mathrm{~min}$ ), $45-48 \% \mathrm{~B}$ (from 5 to $19 \mathrm{~min}$ ), $48-99 \%$ B (from 19 to $21 \mathrm{~min}$ ), $99 \%$ B (from 21 to $23 \mathrm{~min}$ ), $99-25 \%$ B (from 23 to 28 $\mathrm{min}$ ) and $25 \% \mathrm{~B}$ (from 28 to $38 \mathrm{~min}$ ). Compounds were identified at $290 \mathrm{~nm}(\lambda)$ according to their retention time and quantification was performed using a calibration curve of commercial transresveratrol, trans- $\varepsilon$-viniferin and 2-hydroxybenzothiazole that was used as internal standard in crude extracts. LOD and LOQ values were determined for each compounds according to the following equations (from ICH guidelines): $\mathrm{LOD}=3.3 \delta / \mathrm{s}$ and $\mathrm{LOQ}=10 \delta / \mathrm{s}$ where $\delta$ is the standard deviation of noise level and $\mathrm{s}$ is the slope of calibration curves. Purity of Rsv and Vf was evaluated by HPLC-UV as follows: standard calibration was analyzed at different wavelengths: $220 \mathrm{~nm}, 260$ $\mathrm{nm}, 290 \mathrm{~nm}$ and $320 \mathrm{~nm}$. The ratios between peak area at $290 \mathrm{~nm}$ with peaks areas at other wavelengths were determined (Table S4, Supporting information). Then, these ratios were compared to those of compounds in crude extracts and a difference of $\pm 1 \%$ was accepted to validate the purity of the chromatographic peak. 
127 Statistical analysis. Statistical analyses were performed using R software. All data (Rsv and Vf 128 yields of 5 replicates) were tested for normality and homoscedasticity with appropriate tests 129 (ANOVA, Kruskal-Wallis, t-test) with $\alpha=0.05$ defined as threshold for statistical significance.

130 Different letters $(\mathrm{a}, \mathrm{b})$ were used to show the statistical differences between samples as a function 131 of the parameter studied. A same letter is used to shown data non significantly different. When 132 different letters are assigned to different data, it means that they are significantly different from 133 each other. Data with several letters are consequently non significantly different from data with

134 individual letter. In Figure S7 of Supporting information, asterisks were used to show significant 135 statistical differences with * for $p \leq 0.05, * *$ for $p \leq 0.01$, *** for $p \leq 0.001$ and $n s$ for not 136 significant.

\section{RESULTS AND DISCUSSION}

138 Identification of Rsv and Vf in extracts. The retention times of Rsv and Vf (10.2 min and 12.1

139 min respectively) were compared to those of commercial standards solutions (Figure 1). In all 140 crude extracts,

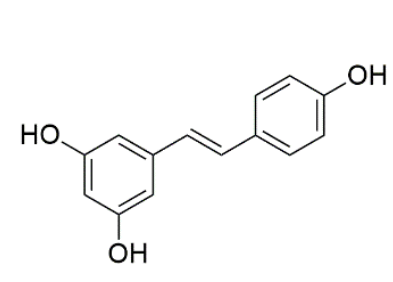

1

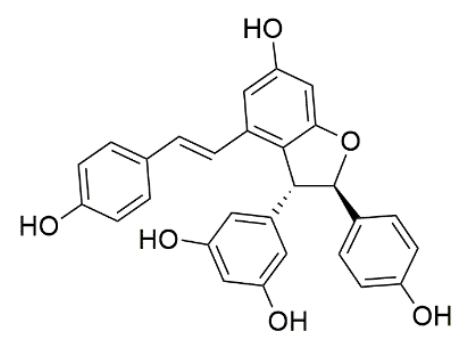

2

144 Figure 1. Chemical structures of trans-resveratrol (1) and its dimer trans- $\varepsilon$-viniferin (2). 
146 both Rsv and Vf were found at detectable and quantifiable levels independently of the type of

147 resource studied (Table 1 and Figure S2, Supporting information). No co-elution phenomenon

148 with cis-resveratrol or other compounds was observed (Figure S3 and Table S4, Supporting

149 information). Using HPLC-UV with a detection at $290 \mathrm{~nm}(\lambda)$, Rsv and Vf respond linearly in the

150 range of 3.75-270 $\mu \mathrm{g} / \mathrm{mL}^{-1}$ and with a correlation coefficient $r>0.99$. Quantified results were then

151 expressed in milligrams of Rsv or Vf extracted per kilograms of dry weight (mg.kg-1 $\left.{ }^{-1}\right)$. At 290

$152 \mathrm{~nm}(\lambda)$ detection, the major compounds detected in Jacquère and Mondeuse grape canes extracts

153 were Rsv and Vf whereas stocks extracts were more complex. Gabaston et al. also reported that

154 Rsv and Vf were the main stilbenoid compounds in grape canes (mixture of Cabernet Sauvignon

155 and Merlot) when Rsv oligomers (as trans- $\varepsilon$-viniferin, isohopeaphenol, $r$-viniferin, ampelopsin A

156 and $r 2$-viniferin) were more abundant in wood (mixture Cabernet Franc and Tannat) and roots

157 (SO4 rootstock). ${ }^{24}$

158

\begin{tabular}{|c|c|c|c|}
\hline Compound & LOD $\left(\mu \mathrm{g} / \mathrm{mL}^{-1}\right)$ & LOQ $\left(\mu \mathrm{g} / \mathrm{mL}^{-1}\right)$ & $t_{R}(\mathrm{~min})$ \\
\hline trans-resveratrol & 0.119 & 0.362 & 10.2 \\
trans- $\varepsilon$-viniferin & 0.153 & 0.465 & 12.1 \\
\hline
\end{tabular}

160 Table 1. Limits of detection (LOD), limits of quantification (LOQ) and retention times $\left(t_{R}\right)$ of 161 trans-resveratrol and trans- $\varepsilon$-viniferin using the HPLC gradient described in experimental section.

163 Impact of vine variety and vineyard age. Grape canes of Jacquère and Mondeuse treated in the

164 same conditions (Vineyard 1, 6 months of storage and particles size $<0.5 \mathrm{~mm}$ ) of 5 years old and 16520 years old vines were compared (Figure 2). Independently of age, Mondeuse grape canes 
166 contained significantly higher levels of Rsv (3759-4636 mg.kg ${ }^{-1}$ dw) than Jacquère (2259-2994

167 mg.kg-1w $)$ whereas Vf levels were similar for both varieties (1620-2016 mg.kg-1 dw). These

168 quantities were in the same range than high levels of Pinot Noir and Gewurztraminer grape canes

169 (Table S1, Supporting information). Another statistical analysis (Figure S5, Supporting

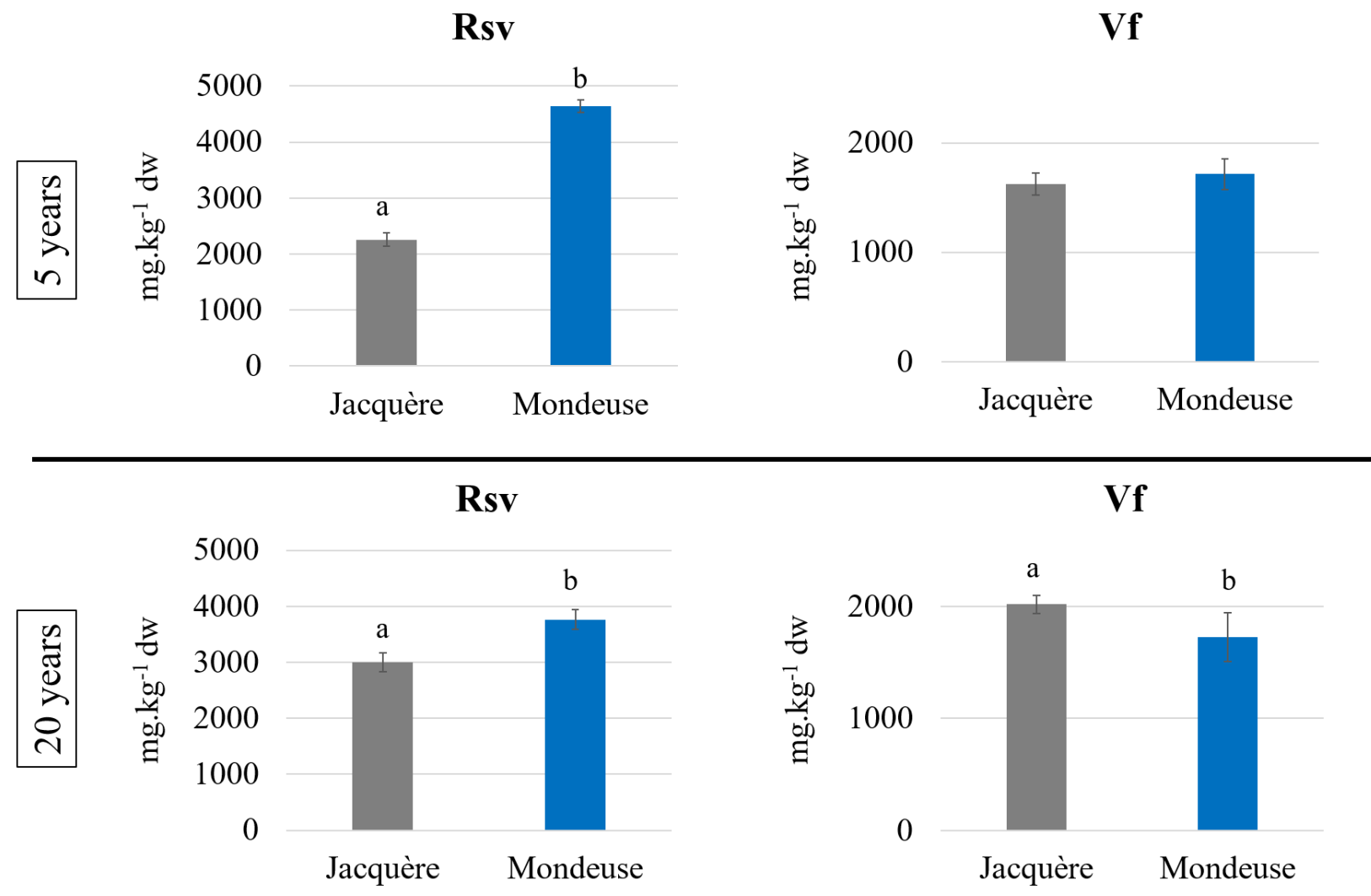

173 Figure 2. Rsv and Vf contents (expressed in milligrams per kilograms of dry weight, mg.kg-1 ${ }^{-1}$ )

174 in Jacquère and Mondeuse grape canes for 5 years old vineyards and 20 years old vineyards. On

175 each histogram, different letters were used to show significant statistical differences between

176 varieties for a same compound and a same age $(\alpha=0.05)$. 
178 information) performed on the impact of age showed that aging of vineyards had a positive effect

179 on stilbenes contents of Jacquère since Rsv and Vf levels increased when the vine becomes older

180 (Figure 2). This tendency was also confirmed with Jacquère grape canes of an another vineyard

181 (Vineyard 2) with Rsv levels switching between $1838 \mathrm{mg} \cdot \mathrm{kg}^{-1} \mathrm{dw}$ for 5 years old vines and 2912

182 mg.kg-1 dw for 20 years old vines (Figure S6, Supporting information). Interestingly, the opposite

183 effect was observed for Mondeuse since Rsv levels were higher for young than for old vines

184 (Figure 2). To the best of our knowledge, it was the first time that a study was conducted on the

185 effect of ageing of vines on their stilbenes contents. Further studies (multiplying the sampling

186 vineyards) are needed to confirm these tendencies and investigate the mechanisms involved.

187 However, according to the results obtained, the selection of appropriate vine age could enhance up

188 to $35 \%$ the Rsv contents extracted.

189 In any case, if Mondeuse grape canes were richer in Rsv than Jacquère grape canes, the opposite

190 effect was observed for the vine stocks (Figure 3). Indeed, the amount of Rsv was 2171-2632

191 mg.kg-1w for Mondeuse stocks and 3537-5148 mg. $\mathrm{kg}^{-1}$ dw for Jacquère stocks (intervals depending

192 on the particles size used). At the same time, Vf contents remained similar in both varieties with

$1934640-5322 \mathrm{mg} \cdot \mathrm{kg}^{-1} \mathrm{dw}$ for Mondeuse variety and $4091-4929 \mathrm{mg} \cdot \mathrm{kg}^{-1} \mathrm{dw}$ for Jacquère variety as seen

194 on Figure 4. However, significant variability could be observed depending on the vineyard (Figure

195 S7, Supporting information). For Jacquère stocks of Vineyard 2, Rsv levels reached up to 6124

196 mg.kg ${ }^{-1}$ ww and Vf levels up to $6667 \mathrm{mg} \cdot \mathrm{kg}^{-1}{ }_{\mathrm{dw}}$ whereas for Mondeuse Rsv levels did not exceed

$1971953 \mathrm{mg} \cdot \mathrm{kg}^{-1}{ }_{\mathrm{dw}}$ and Vf levels $4094 \mathrm{mg} \cdot \mathrm{kg}^{-1} \mathrm{dw}$. Németh et al. observed the opposite effect for Rsv

198 since the authors noted a higher concentration in grape canes than in roots of Merlot grafted on

199 TK5BB rootstock. ${ }^{25}$ This divergence could be explained by several factors including year to year

200 variations and different rootstocks. ${ }^{26-29}$ 
201 Whether it is for grape canes or stocks, lots of factors could explain the differences observed 202 between the levels of the two exploitations. The UV-exposition of vineyards depending directly of 203 their location impacts the stilbenes accumulation in grape canes as well as the soil composition or 204 the fungal pressure. ${ }^{30-32}$ Viticultural practices, as leaf removal, irrigation or nitrogen fertilization 205 and differing from a vineyard to another, could also be responsible for these variations. ${ }^{33,34}$

206 Impact of particles size. A patent published in 2015 mentioned that particles size of Melon de 207 Bourgogne grape canes influences Rsv and Vf yield in a classical maceration in ethanol/water $20880: 20(\mathrm{v} / \mathrm{v})$ during $15 \mathrm{~min}$ followed by an extrusion of the mixture. ${ }^{35}$ According to the patent, 4 $209 \mathrm{~mm}$ was better than 8 and $1 \mathrm{~mm}$ to recover both compounds (respectively 915, 387 and $764 \mathrm{mg}^{\mathrm{kg}} \mathrm{kg}^{-}$ $210{ }_{\mathrm{dw}}$ for Rsv and 8170, 6440 and $5482 \mathrm{mg} \cdot \mathrm{kg}^{-1} \mathrm{dw}$ for Vf). In the present study, grape canes of 211 Jacquère variety (Vineyard 1, 20 years old, 6 months of storage) and Mondeuse (Vineyard 1, 20 212 years old, 9 months of storage) were crushed at different particles sizes $(<0.2 \mathrm{~mm},<0.5 \mathrm{~mm},<1$

$213 \mathrm{~mm}$ and $<4 \mathrm{~mm}$ ) to investigate the effect of particles size on Rsv and Vf extraction. Results on 214 Figure 3 showed higher yields while increasing particles size for Rsv whereas the opposite effect 215 was observed for Vf. These results were observed for both varieties. For Jacquère, Rsv yields were 216 improved up to $20 \%$ when particles size $<4 \mathrm{~mm}$ was used instead of $<0.2 \mathrm{~mm}$ and Vf yields 217 decreased of $50 \%$. Gorena et al. firstly demonstrated that intact canes are required to allow 218 stilbenes accumulation (mainly due to Rsv contents increase) during storage while in $<20$ mesh 219 (i.e. $<0.84 \mathrm{~mm}$ ) samples no accumulation occurs. ${ }^{36}$ Similarly, Billet et al. recently mentioned that 220 cutting grape canes in small sections of 5 and $10 \mathrm{~mm}$ before storage causes a faster Rsv 
Jacquère

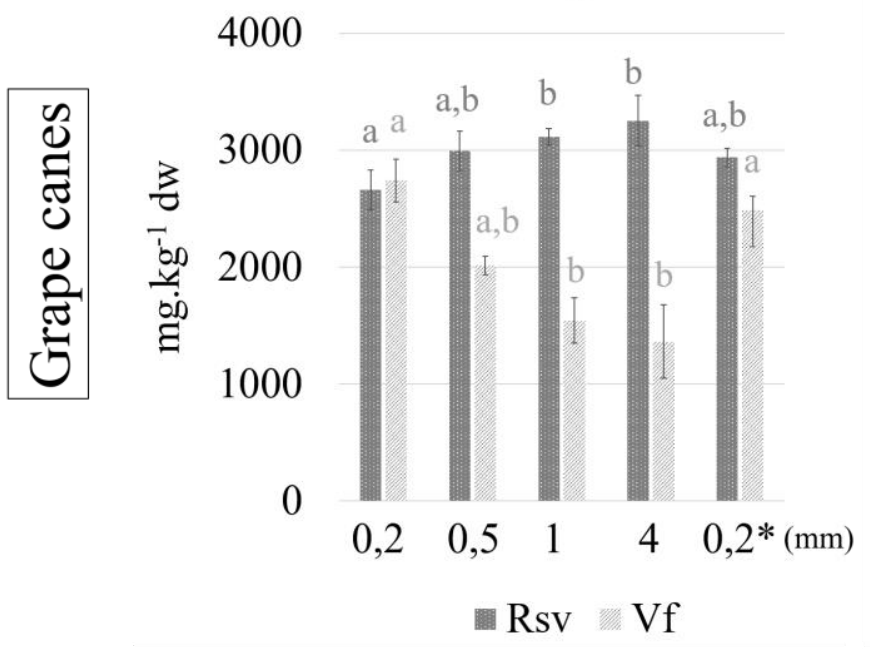

Jacquère

6000

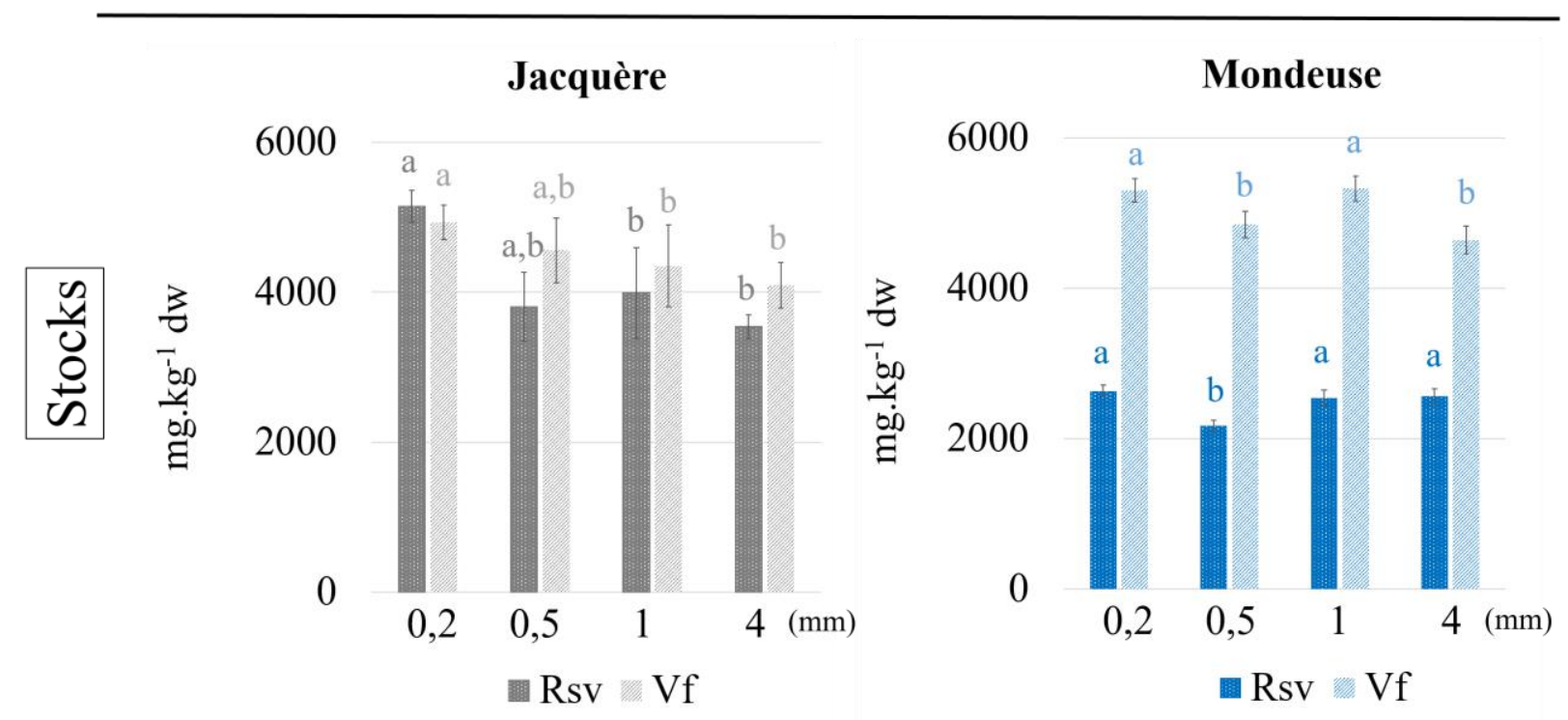

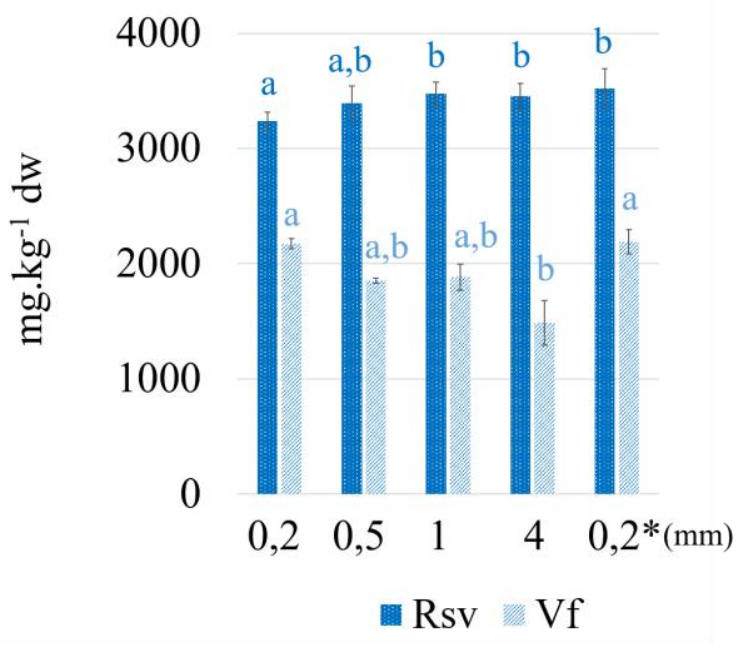

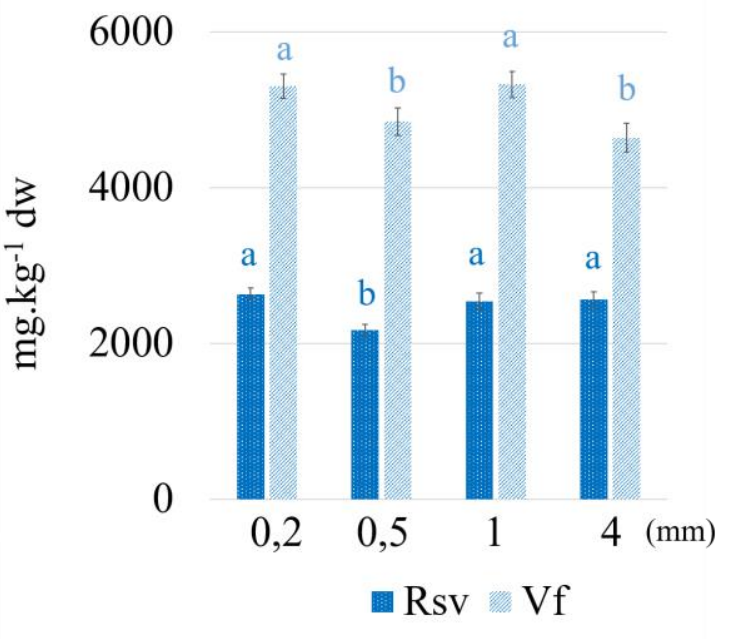

223 Figure 3. Rsv and Vf contents (expressed in milligrams per kilograms of dry weight, $\mathrm{mg} \cdot \mathrm{kg}^{-1} \mathrm{dw}$ )

224 in Jacquère and Mondeuse grape canes and stocks in function of particles size (mm). On each

225 histogram, different letters were used to show significant statistical differences between particles

226 sizes for a same compound and a variety $(\alpha=0.05) .0 .2 *$ : batch of $<4 \mathrm{~mm}$ powder crushed at $<$ 
229 accumulation in comparison with $2 \mathrm{~mm}$ sections ${ }^{37}$ In the present work, it was shown that larger

230 was the particles size (in the range of $0.2-4 \mathrm{~mm}$ ), better was the plant response to mechanical

231 wounding in terms of Rsv accumulation. This behavior is really unexpected since grape canes were

232 stored during 6 and 9 months and were almost dry (2-3 grams of water per 100 grams of grape

233 canes). However, Ewald et al. also noted a biological response to drought stress of grape canes

234 stored up to 30 months, especially in the case of Rsv. ${ }^{28}$

235 In addition, it was demonstrated for the first time that the biosynthesis of Vf is not impacted by

236 grinding. Extraction efficiency of this compound is only ruled by mass transfer limitation since a

237 secondary grinding of the particles size $<4 \mathrm{~mm}$ batch at $<0.2 \mathrm{~mm}$ allowed to recover yields

238 obtained for the first $<0.2 \mathrm{~mm}$ batch $\left(0.2^{*}\right.$ on Figure 3$) .{ }^{38,39}$

239 Interestingly, extraction efficiency of targeted compounds in stocks decreased when the particles

240 size increased probably showing the absence of biological response under mechanical stress in this

241 part of the plant. This tendency was also observed in stocks of Vineyard 2 (Figure S7, Supporting

242 information).

244 Impact of storage duration. There are numerous studies on the evolution of stilbenes contents in 245 grape canes during their storage. ${ }^{12,18,19}$ The reported works admit that there is a peak of Rsv 246 accumulation in grape canes between 6 weeks and 6 months of storage. In the present work, impact 247 of storage on compound accumulation was evaluated on grape canes of Jacquère and Mondeuse 248 varieties of the same exploitation (Vineyard 1) and the same age (20 years). Shoots were stored 249 for 9 months at room temperature with collections at 2,6 and 9 months and crushing at $<0.2 \mathrm{~mm}$.

250 The results presented on Figure 4 showed similar levels for Rsv and Vf for both varieties at 2 251 months of storage. At 6 months, Rsv levels increased significantly up to 1.5 fold for Jacquère and 
252 up to 2 fold for Mondeuse whereas Vf contents decreased slightly. After 9 months of storage, Rsv 253 levels started to decrease and Vf levels continued to decrease, specially for Mondeuse with a 254 significant loss of $30 \%$ when compared to 2 months levels (16\% for Jacquère). Rsv increase for 255 the first 6 months was also observed by Cebrián et al. whereas Gorena et al. and Houillée et al. 256 highlighted Rsv increase only until 2-3 months followed by a decay for various grapevine varieties 257 258

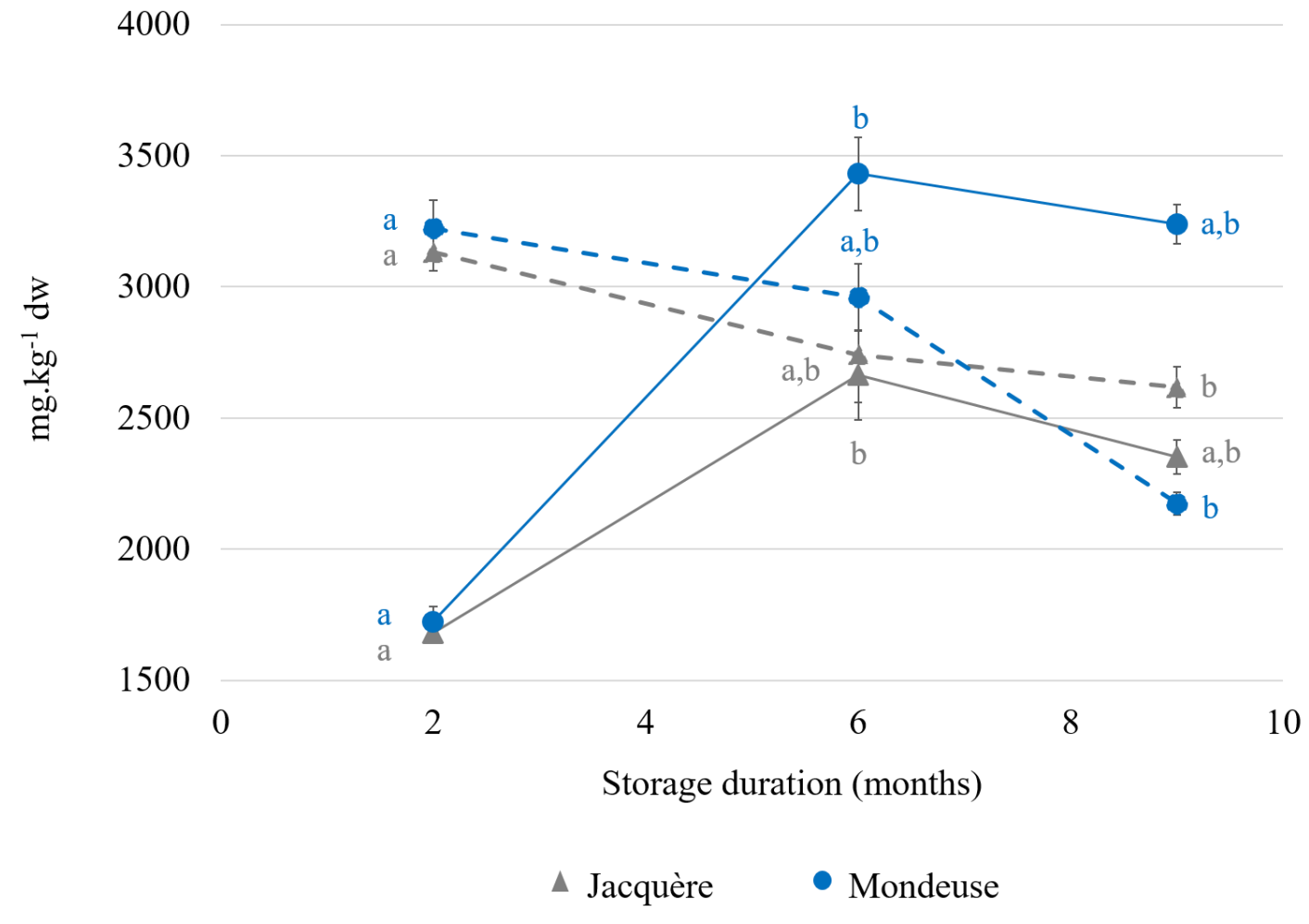

261 Figure 4. Rsv (solid line) and Vf (dashed line) contents (expressed in miligrams per kilograms of 262 dry weight, $\mathrm{mg} \cdot \mathrm{kg}^{-1} \mathrm{dw}$ ) in Jacquère and Mondeuse grape canes depending on their storage duration 263 at room temperature. Different letters were used to show significant statistical differences between 264 durations for a same compound and a same variety $(\alpha=0.05)$. 
266 showing that it is not a phenonomenom proper to Jacquère and Mondeuse varieties. ${ }^{36,41,40}$ The

267 divergence between the Rsv accumulation durations could be due to several storage specific

268 factors. Indeed, temperature, relative humidity and UV exposition of storage location could also

269 affect stilbenes accumulation. ${ }^{40,42,43}$ Concerning Vf contents evolution over time, to the best of our

270 knowledge, it was the first time that a considerable and constant decrease during storage was

271 mentioned.

272

273 CONCLUSIONS

274 Jacquère and Mondeuse grape canes and stocks from Savoie Mont Blanc territory represent 275 valuable sources of trans-resveratrol (Rsv) and trans- $\varepsilon$-viniferin (Vf) with contents up to 6124 276 mg. $\mathrm{kg}^{-1} \mathrm{dw}$ for Rsv and up to $6667 \mathrm{mg} \cdot \mathrm{kg}^{-1} \mathrm{dw}$ for Vf. However, it must be not forgotten that 277 considerable variations are observed from year to year. ${ }^{26,28,29,44}$ Nevertheless, this study also 278 highlighted the variability that could be induced by several pre-extraction parameters influencing 279 recovery of Rsv and Vf, some of which could be optimized. Age of vineyards seems to have an 280 effect on the stilbenes content of grape canes and further investigations are needed to confirm this 281 tendency. Remarkably, the increase of particles size of the woody material entailed an 282 enhancement of Rsv extraction in Jacquère and Mondeuse grape canes with an optimum for 283 particles size $<4 \mathrm{~mm}$ in comparison with $<0.2 \mathrm{~mm},<0.5 \mathrm{~mm}$ and $<1 \mathrm{~mm}$. This resulted from an 284 accumulation of Rsv by plant response to a mechanical stress whereas Vf biosynthesis was not 285 impacted. Further investigations are needed to better understand this phenomenon. Comparably to 286 other works, Vf contents in Jacquère and Mondeuse grape canes decreased considerably during 9 287 months of storage while Rsv accumulated effectively during 6 months and then decreased. The 288 common practice of open-air burning justified by the fear of diseases propagation in viticultural 
289 community (especially in the case of stocks) will be no longer possible on Savoie Mont Blanc

290 territory. Indeed, a prefectoral decree implemented in 2017 prohibits open-air burning of

291 agricultural waste including viticultural waste. This decision will bring an important amount of 292 waste with high contents of Rsv and Vf available for chemical valorization.

294 ASSOCIATED CONTENT

295 Supporting Information: Table of Rsv and Vf contents in Pinot Noir and Gewurztraminer grape 296 canes from the literature; HPLC-UV chromatograms from experiments; Rsv and Vf contents in 297 Jacquère and Mondeuse grape canes in function of the age of vines, the vineyard of origin and 298 plant material particles size.

299

300 AUTHOR INFORMATION

301 Corresponding Author

$302 *$ Dr. Gregory Chatel. E-mail: gregory.chatel@univ-smb.fr Twitter: @gregory_chatel

303 ORCID: $\underline{000-0001-8814-812 \mathrm{X}}$

304 ORCID Authors:

305 Marion ZWINGELSTEIN ORCID: 0000-0002-6267-9130

306 Micheline DRAYE ORCID: 0000-0002-8216-0184

307 Jean-Luc BESOMBES ORCID: 0000-0002-3793-3256

308 Gregory CHATEL ORCID: 000-0001-8814-812X

309

$310 \quad$ Notes

311 The authors declare no competing financial interest. 
314 The authors gratefully acknowledge the Agence de l'Environnement et de Maitrîse de l'Energie

315 (ADEME) and the Conseil Savoie Mont Blanc (CSMB) for the awarding of the PhD scholarship

316 to Marion Zwingelstein. They also thank the Université Savoie Mont Blanc and its foundation for

317 their final supports. They also thank participating winegrowers for plant material providing and

318 their willingness. Finally, they thank Thibault Masset (Laboratoire de Chimie Moléculaire et

319 Environnement, Univ. Savoie Mont Blanc, France) for helpful discussions on statistical analysis.

\section{REFERENCES}

(1) ADEME. Rapport de tendances à l'horizon 2017 pour l'ADEME. 2012. https://www.ademe.fr/rapport-tendances-a-lhorizon-2017-lademe (accessed October 26, 2018).

(2) Abosede, I. A.; et al. Biomass Valorization: Agricultural Waste in Environmental Protection, Phytomedicine and Biofuel Production. In Biomass Volume Estimation and Valorization for Energy; Tumuluru, J. S., Eds.; IntechOpen, 2017.

(3) Organisation Internationale de la Vigne et du Vin. Eléments de conjoncture mondiale. 2018. http://www.oiv.int/public/medias/5952/fr-oiv-note-de-conjoncture-avril-2018.pdf （accessed October 23, 2018).

(4) Angelov, G.; Boyadzhiev, L.; Georgieva, S. Useful Bioactive Substances from Wastes: Recovery of Trans-Resveratrol from Grapevine Stems. Open Chem. Eng. J. 2016, 10 (1), 4-9.

(5) Sánchez-Gómez, R.; Zalacain, A.; Alonso, G. L.; Salinas, M. R. Vine-Shoot Waste Aqueous Extracts for Re-Use in Agriculture Obtained by Different Extraction Techniques: Phenolic, Volatile, and Mineral Compounds. J. Agric. Food Chem. 2014, 62 (45), 10861-10872.

(6) Jeandet, P.; Delaunois, B.; Conreux, A.; Donnez, D.; Nuzzo, V.; Cordelier, S.; Clément, C.; Courot, E. Biosynthesis, Metabolism, Molecular Engineering, and Biological Functions of Stilbene Phytoalexins in Plants. BioFactors Oxf. Engl. 2010, 36 (5), 331-341.

(7) Rivière, C.; Pawlus, A. D.; Mérillon, J.-M. Natural Stilbenoids: Distribution in the Plant Kingdom and Chemotaxonomic Interest in Vitaceae. Nat. Prod. Rep. 2012, 29 (11), 1317-1333.

(8) Roubelakis-Angelakis, K. A. Molecular Biology \& Biotechnology of the Grapevine; Kluwer Academic Publishers, 2001.

(9) Billard, C.; Izard, J.-C.; Roman, V.; Kern, C.; Mathiot, C.; Mentz, F.; Kolb, J.-P. Comparative Antiproliferative and Apoptotic Effects of Resveratrol, $\epsilon$-Viniferin and Vine-Shots Derived Polyphenols (Vineatrols) on Chronic B Lymphocytic Leukemia Cells and Normal Human Lymphocytes. Leuk. Lymphoma 2002, 43 (10), 1991-2002.

(10) Romain, C.; Gaillet, S.; Carillon, J.; Vidé, J.; Ramos, J.; Izard, J.-C.; Cristol, J.-P.; Rouanet, J.-M. Vineatrol and Cardiovascular Disease: Beneficial Effects of a Vine-Shoot Phenolic Extract in a Hamster Atherosclerosis Model. J. Agric. Food Chem. 2012, 60 (44), 11029-11036.

(11) Baur, J. A.; Pearson, K. J.; Price, N. L.; Jamieson, H. A.; Lerin, C.; Kalra, A.; Prabhu, V. V.; Allard, J. S.; Lopez-Lluch, G.; Lewis, K.; et al. Resveratrol Improves Health and Survival of Mice on a High-Calorie Diet. Nature 2006, 444 (7117), 337-342. 
(12) Farina, A.; Ferranti, C.; Marra, C. An Improved Synthesis of Resveratrol. Nat. Prod. Res. 2006, 20, 247-252.

(13) Lindgren, A. E. G.; Öberg, C. T.; Hillgren, J. M.; Elofsson, M. Total Synthesis of the Resveratrol Oligomers ( \pm )- Ampelopsin B and ( \pm )- $\epsilon$ - Viniferin. Eur. J. Org. Chem. 2016, 2016 (3), 426-429.

(14) Chen, H.; Deng, Q.; Ji, X.; Zhou, X.; Kelly, G.; Zhang, J. Glucose Oxidase-Assisted Extraction of Resveratrol from Japanese Knotweed (Fallopia Japonica). New J. Chem. 2016, 40 (9), 8131-8140.

(15) Singh, C. K.; Liu, X.; Ahmad, N. Resveratrol, in Its Natural Combination in Whole Grape, for Health Promotion and Disease Management. Ann. N. Y. Acad. Sci. 2015, 1348 (1), 150-160.

(16) Li, M.; Kildegaard, K. R.; Chen, Y.; Rodriguez, A.; Borodina, I.; Nielsen, J. De Novo Production of Resveratrol from Glucose or Ethanol by Engineered Saccharomyces Cerevisiae. Metab. Eng. 2015, $32,1-11$.

(17) Chastang, T. Etude de la synthèse du resvératrol et de ses dérivés (viniférines) par des suspensions de cellules de vigne et optimisation de la production en bioréacteur. Ph.D. Dissertation, Ecole Centrale Paris, 2014.

(18) Lambert, C.; Richard, T.; Renouf, E.; Bisson, J.; Waffo-Téguo, P.; Bordenave, L.; Ollat, N.; Mérillon, J.-M.; Cluzet, S. Comparative Analyses of Stilbenoids in Canes of Major Vitis Vinifera L. Cultivars. J. Agric. Food Chem. 2013, 61 (47), 11392-11399.

(19) Vergara, C.; von Baer, D.; Mardones, C.; Wilkens, A.; Wernekinck, K.; Damm, A.; Macke, S.; Gorena, T.; Winterhalter, P. Stilbene Levels in Grape Cane of Different Cultivars in Southern Chile: Determination by HPLC-DAD-MS/MS Method. J. Agric. Food Chem. 2012, 60 (4), 929-933.

(20) Guerrero, R. F.; Biais, B.; Richard, T.; Puertas, B.; Waffo-Teguo, P.; Merillon, J.-M.; Cantos-Villar, E. Grapevine Cane's Waste Is a Source of Bioactive Stilbenes. Ind. Crops Prod. 2016, 94, 884-892.

(21) Piñeiro, Z.; Guerrero, R. F.; Fernández-Marin, M. I.; Cantos-Villar, E.; Palma, M. UltrasoundAssisted Extraction of Stilbenoids from Grape Stems. J. Agric. Food Chem. 2013, 61 (51).

(22) Piñeiro, Z.; Marrufo-Curtido, A.; Vela, C.; Palma, M. Microwave-Assisted Extraction of Stilbenes from Woody Vine Material. Food Bioprod. Process. 2017, 103, 18-26.

(23) Karacabey, E.; Mazza, G.; Bayındırlı, L.; Artık, N. Extraction of Bioactive Compounds from Milled Grape Canes (Vitis Vinifera) Using a Pressurized Low-Polarity Water Extractor. Food Bioprocess Technol. 2012, 5 (1), 359-371.

(24) Gabaston, J.; Cantos-Villar, E.; Biais, B.; Waffo-Teguo, P.; Renouf, E.; Corio-Costet, M.-F.; Richard, T.; Mérillon, J.-M. Stilbenes from Vitis Vinifera L. Waste: A Sustainable Tool for Controlling Plasmopara Viticola. J. Agric. Food Chem. 2017, 65 (13), 2711-2718.

(25) Németh, G.; Hegyi, O.; Dunai, A.; Kocsis, L. Stilbenes in the Different Organs of Vitis Vinifera Cv. Merlot Grafted on Teleki Kober 5BB Rootstock. OENO One 2017, 51 (3), 323-328.

(26) Nèmeth, G.; Molnár, Z.; Podmaniczky, P.; Nyitrai-Sárdy, D.; Kállay, M.; Dunai, A.; Kocsis, L. Trans-Resveratrol Content in Grape Cane and Root of Different Scion-Rootstock Combinations. Mitteilungen Klosterneubg. Rebe Wein Obstbau Früchteverwert. 2017, 67 (4), 256-264.

(27) Gabaston, J.; Leborgne, C.; Waffo- Teguo, P.; Valls, J.; Pinto, A. P.; Richard, T.; Cluzet, S.; Mérillon, J.-M. Wood and Roots of Major Grapevine Cultivars and Rootstocks: A Comparative Analysis of Stilbenes by UHPLC-DAD-MS/MS and NMR. Phytochem. Anal. $O(0)$.

(28) Ewald, P.; Delker, U.; Winterhalter, P. Quantification of Stilbenoids in Grapevine Canes and Grape Cluster Stems with a Focus on Long-Term Storage Effects on Stilbenoid Concentration in Grapevine Canes. Food Res. Int. 2017, 100, 326-331.

(29) Bavaresco, L.; Civardi, S.; Pezzutto, S.; Gatti, M.; Mattivi, F. Role of the Genotype on Stilbene Synthesis in Grapevine. Acta Hortic. 2009, No. 827, 347-350.

(30) Guerrero, R. F.; Cantos-Villar, E.; Puertas, B.; Richard, T. Daily Preharvest UV-C Light Maintains the High Stilbenoid Concentration in Grapes. J. Agric. Food Chem. 2016, 64 (25), 5139-5147.

(31) Acuña-Avila, P. E.; Vásquez-Murrieta, M. S.; Franco Hernández, M. O.; López-Cortéz, M. del S. Relationship between the Elemental Composition of Grapeyards and Bioactive Compounds in the Cabernet Sauvignon Grapes Vitis Vinífera Harvested in Mexico. Food Chem. 2016, 203, 79-85. 
403

404

405

406

407

408

409

410

411

412

413

414

415

416

417

418

419

420

421

422

423

424

425

426

427

428

429

430

431

432

433

434

435

436

437

438

439

440

441

442

443

444

445

446

447

448

449

450

451
(32) Houillé, B.; Besseau, S.; Delanoue, G.; Oudin, A.; Papon, N.; Clastre, M.; Simkin, A. J.; Guérin, L.; Courdavault, V.; Giglioli-Guivarc'h, N.; et al. Composition and Tissue-Specific Distribution of Stilbenoids in Grape Canes Are Affected by Downy Mildew Pressure in the Vineyard. J. Agric. Food Chem. 2015, 63 (38), 8472-8477.

(33) Keller, M.; Steel, C. C.; Creasy, G. L. Stilbene Accumulation in Grapevine Tissues: Developmental and Environmental Effects. Acta Hortic. 2000, 514, 275-286.

(34) Cavaliere, C.; Foglia, P.; Marini, F.; Samperi, R.; Antonacci, D.; Laganà, A. The Interactive Effects of Irrigation, Nitrogen Fertilisation Rate, Delayed Harvest and Storage on the Polyphenol Content in Red Grape (Vitis Vinifera) Berries: A Factorial Experimental Design. Food Chem. 2010, 122 (4), 1176-1184.

(35) Soum, S.; Piccirilli, A.; Bataille, F. Method for Obtaining Polyphenols from a Vegetable Raw Material Containing Same. FR2998296 (B1), March 6, 2015.

(36) Gorena, T.; Saez, V.; Mardones, C.; Vergara, C.; Winterhalter, P.; von Baer, D. Influence of PostPruning Storage on Stilbenoid Levels in Vitis Vinifera L. Canes. Food Chem. 2014, 155 (Supplement C), 256-263.

(37) Billet, K.; Houillé, B.; Besseau, S.; Mélin, C.; Oudin, A.; Papon, N.; Courdavault, V.; Clastre, M.; Giglioli-Guivarc'h, N.; Lanoue, A. Mechanical Stress Rapidly Induces E-Resveratrol and EPiceatannol Biosynthesis in Grape Canes Stored as a Freshly-Pruned Byproduct. Food Chem. 2018, 240, 1022-1027.

(38) Özkal, S. G.; Yener, M. E.; Bayındırl1, L. Mass Transfer Modeling of Apricot Kernel Oil Extraction with Supercritical Carbon Dioxide. J. Supercrit. Fluids 2005, 35 (2), 119-127.

(39) Molero Gómez, A.; Pereyra López, C.; Martinez de la Ossa, E. Recovery of Grape Seed Oil by Liquid and Supercritical Carbon Dioxide Extraction: A Comparison with Conventional Solvent Extraction. Chem. Eng. J. Biochem. Eng. J. 1996, 61 (3), 227-231.

(40) Houillé, B.; Besseau, S.; Courdavault, V.; Oudin, A.; Glévarec, G.; Delanoue, G.; Guérin, L.; Simkin, A. J.; Papon, N.; Clastre, M.; et al. Biosynthetic Origin of E-Resveratrol Accumulation in Grape Canes during Postharvest Storage. J. Agric. Food Chem. 2015, 63 (5), 1631-1638.

(41) Cebrián, C.; Sánchez-Gómez, R.; Salinas, M. R.; Alonso, G. L.; Zalacain, A. Effect of Post-Pruning Vine-Shoots Storage on the Evolution of High-Value Compounds. Ind. Crops Prod. 2017, 109, 730736.

(42) Sáez, V.; Gayoso, C.; Riquelme, S.; Pérez, J.; Vergara, C.; Mardones, C.; von Baer, D. C18 CoreShell Column with in-Series Absorbance and Fluorescence Detection for Simultaneous Monitoring of Changes in Stilbenoid and Proanthocyanidin Concentrations during Grape Cane Storage. J. Chromatogr. B 2018, 1074-1075, 70-78.

(43) Guerrero, R. F.; Puertas, B.; Fernández, M. I.; Palma, M.; Cantos-Villar, E. Induction of Stilbenes in Grapes by UV-C: Comparison of Different Subspecies of Vitis. Innov. Food Sci. Emerg. Technol. 2010, 11 (1), 231-238.

(44) Tř́ska, J.; Vrchotová, N.; Balík, J.; Soural, I.; Sotoláŕ, R. Variability in the Content of TransResveratrol, Trans- $\varepsilon$-Viniferin and R2-Viniferin in Grape Cane of Seven Vitis Vinifera L. Varieties during a Three-Year Study. Molecules 2017, 22 (6), 928. 


\section{SYNOPSIS}

453 The present work provides new data on the impact of pre-extraction parameters in terms of high-

454 value compounds recovery from typical Savoie Mont Blanc territory grape canes and grapevine 455 stocks.

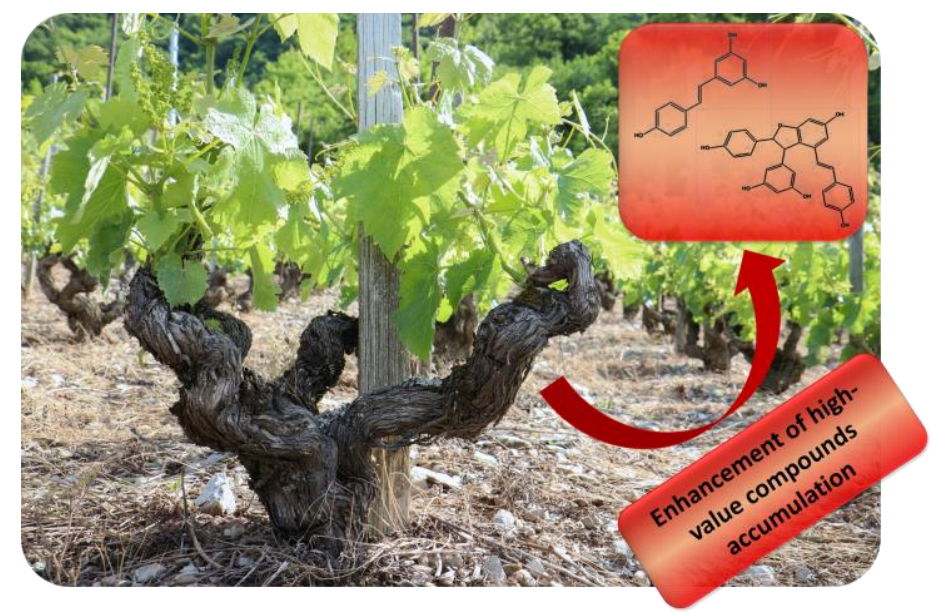

